\title{
TUNING OF ADJUSTABLE PARAMETERS OF HWA HARDWARE DURING DEVELOPMENT OF NEW TYPE VENTILATION SYSTEM
}

\author{
Wawrzyniak S.*, Peszyński K.**
}

\begin{abstract}
The article presents the results of testing adjustable parameters of HWA hardware: sampling frequency and number of samples necessary to ensure a short measurement time and appropriate test quality. There is also presented the general test stand used when investigating the properties of flow in ventilation ducts of rectangle cross-section with rounded corners. Finally, the air velocity distributions along the symmetry axis of the selected channel related to the values calculated using the FLUENT code are presented.
\end{abstract}

Keywords: Turbulent air velocity, Sampling, HWA, Ventilation duct.

\section{Introduction}

During the works related to the development of the new ventilation system (Peszyński et al., 2017) point air measurement using the hot-wire anemometry method was used (Brunn, 1995 and Dantec, 1996) - see Fig. 1.

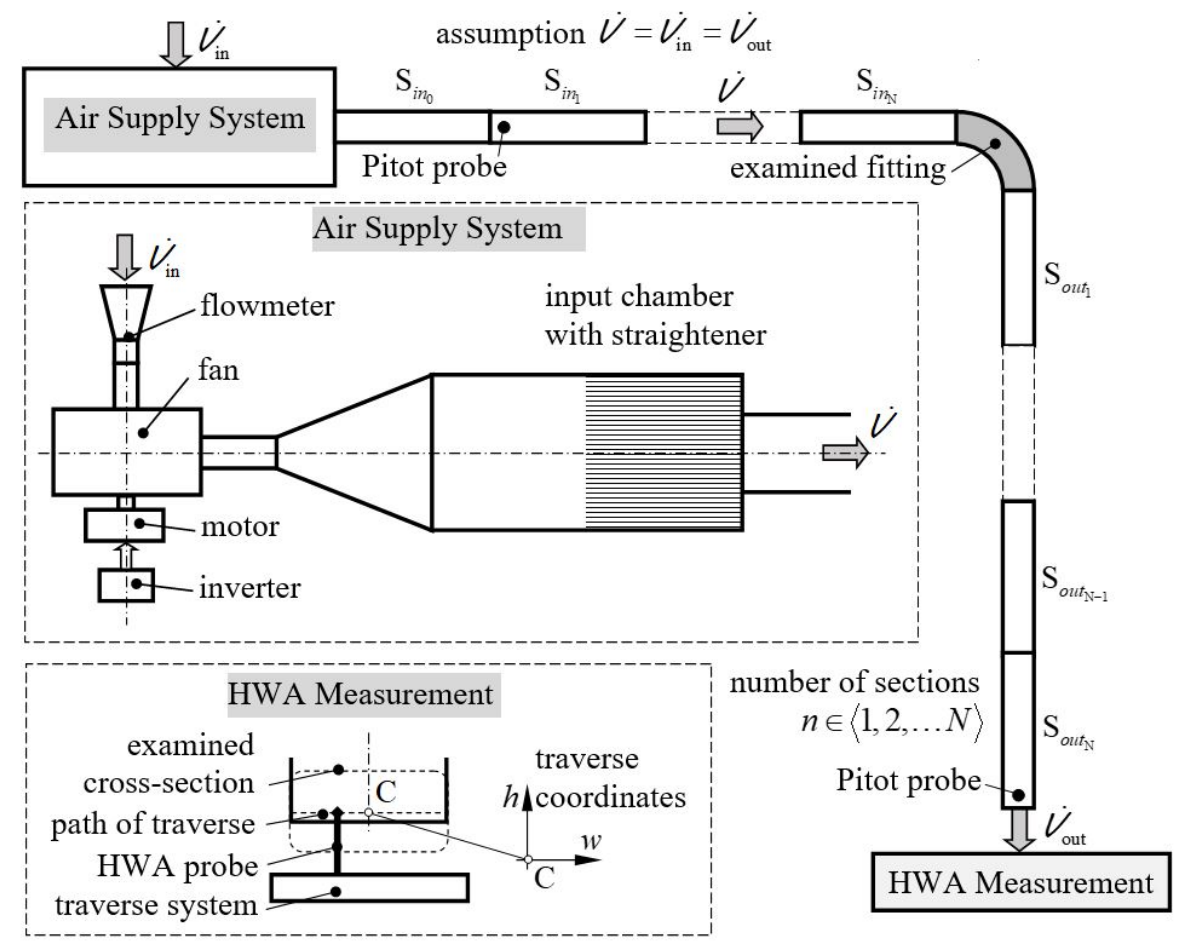

Fig. 1: Test stand.

The velocity distribution was measured along the symmetry axes of the duct at its outlet (Fig. 1 down left and Fig. 3c). This distribution was the basis for the numerical determination of the flow rate in the examined

* $\quad$ Assist. Prof. Sylwester Wawrzyniak, PhD.: UTP University of Science and Technology, Al. prof. S. Kaliskiego; 85-796 Bydgoszcz; PL, sylwester.wawrzyniak@utp.edu.pl

** Assoc. Prof. Kazimierz Peszyński, PhD.: UTP University of Science and Technology, Al. prof. S. Kaliskiego; 85-796 Bydgoszcz; PL, kazimerz.peszynski@utp.edu.pl 
duct. The tests were carried out for the same average velocity $v_{\text {avg }}=5 \mathrm{~m} \cdot \mathrm{s}^{-1}$ in cross-section, this air velocity is the result of noise limitation during ventilation systems operation. This criterion was adopted because usually accepted criterion of a fixed Reynolds number $R e$ failed during the tests, the assumption $R e=$ const led to too small flow rates, this caused transverse movements in the ducts, the flow was very unstable. Results in Fig. 2 are for ventilation duct $W \times H=0.8 \mathrm{~m} \times 0.5 \mathrm{~m}$ and $R e=100000$.

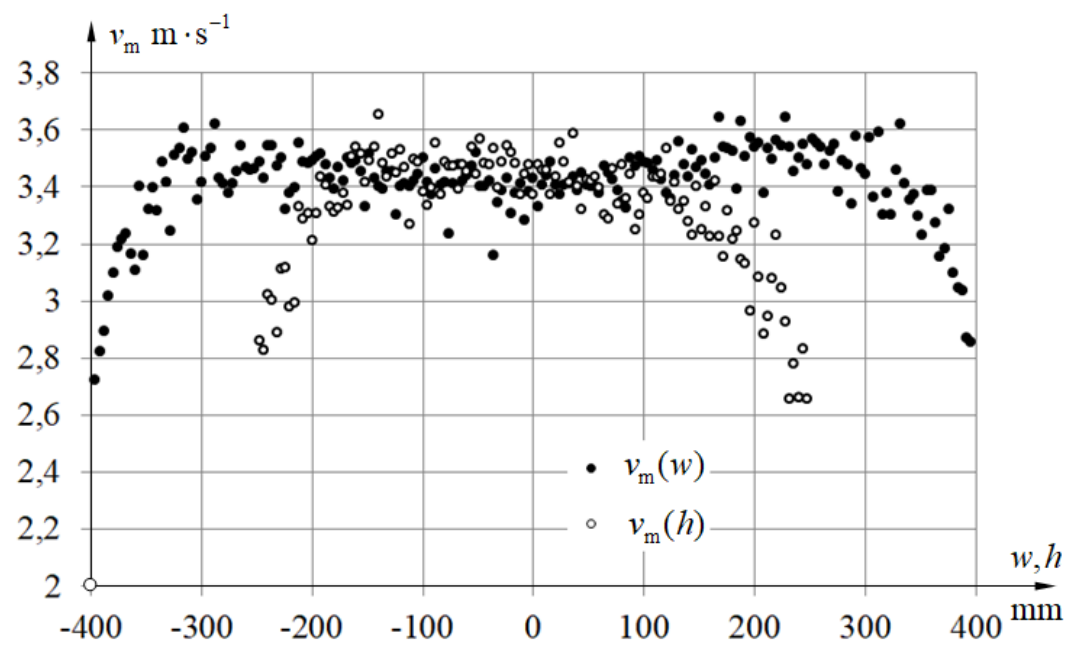

Fig. 2: Distribution of measured velocities for too low average velocity.

\section{Tuning of HWA hardware parameters}

Due to the large number of tested ventilation ducts, one of the important parameters was the time of measurement in one point.

a) $f=10.00 \mathrm{kHz} ; \quad n=262144$

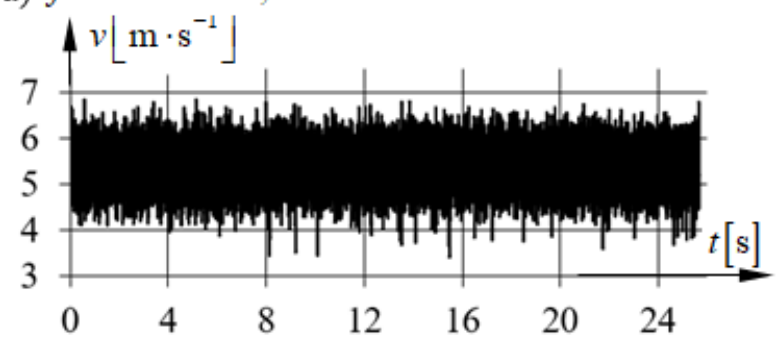

c) $f=0.015 \mathrm{kHz} ; \quad n=128$

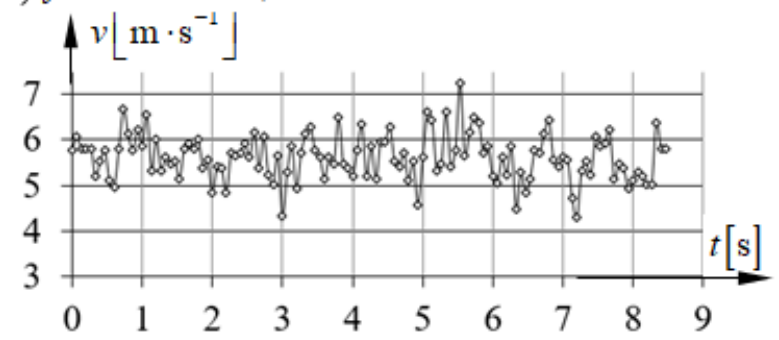

e) $f=1.00 \mathrm{kHz} ; \quad n=8$

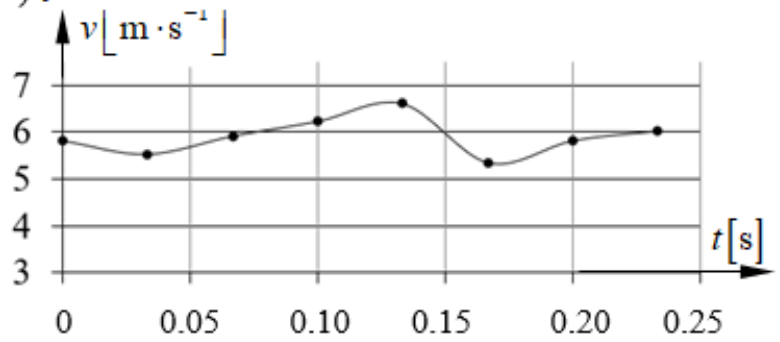

b) $f=1.00 \mathrm{kHz} ; \quad n=4096$

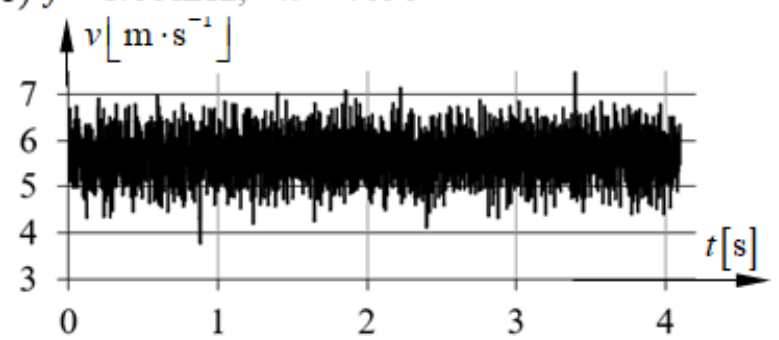

d) $f=1.00 \mathrm{kHz} ; \quad n=128$

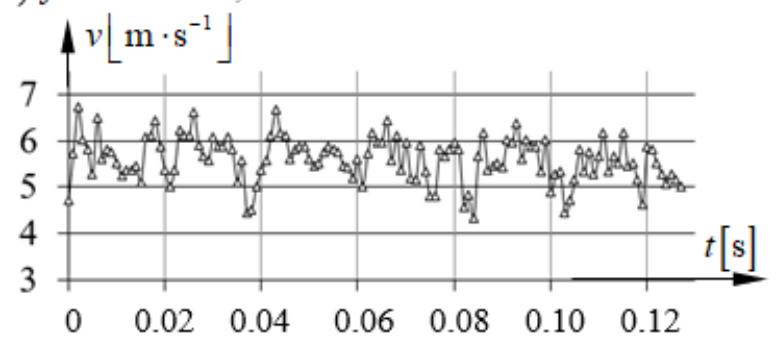

f) $f=0.03 \mathrm{kHz} ; \quad n=8$

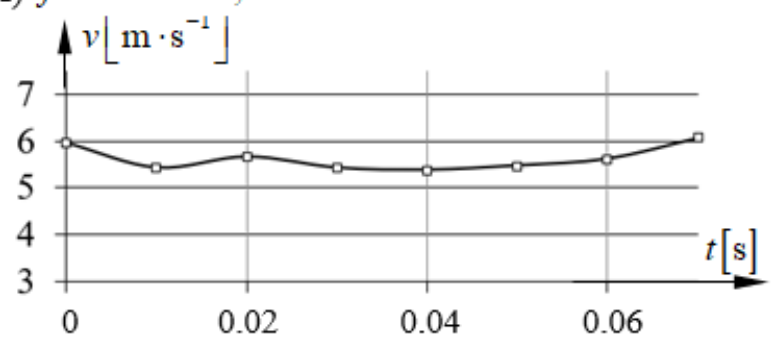

Fig. 3: Testing tuning parameters of HWA hardware. 
The analysis of HWA hardware parameters settings carried out during the measurements was aimed at choosing the "optimal" set of sampling frequencies and the number of samples allowing for the shortest duration of measurements with satisfactory accuracy of the measured air velocity. The number of different cross-sections of ventilation ducts declared by the manufacturer is to be 79 . For maximum cross-section with a maximum dimension equal $W \times H=2.0 \mathrm{~m} \times 1.2 \mathrm{~m}$ we would have 501 points in one axis for a constant step $s=4 \mathrm{~mm}$, which would lead to an unacceptably time-consuming measurement with a long measuring time at a single point.

The measurement time in one point results $t_{\mathrm{m}}=n / f$ from the adopted sampling frequency $f$ and number of samples $n$. The total measurement time for one ventilation duct was the sum of the measurement times at a given point and the times the probe was moved between individual points, as well as the waiting time to stabilization the flow disturbed by the probe movement.

Fig. 3 presents the results of measurements of the velocity of air flowing out of the ventilation duct carried out at one measuring point (in the axis of symmetry of the tested duct). For the results obtained, the average value of the measurement result was calculated and the relative error was calculated. The results of these calculations are presented in Tab. 1.

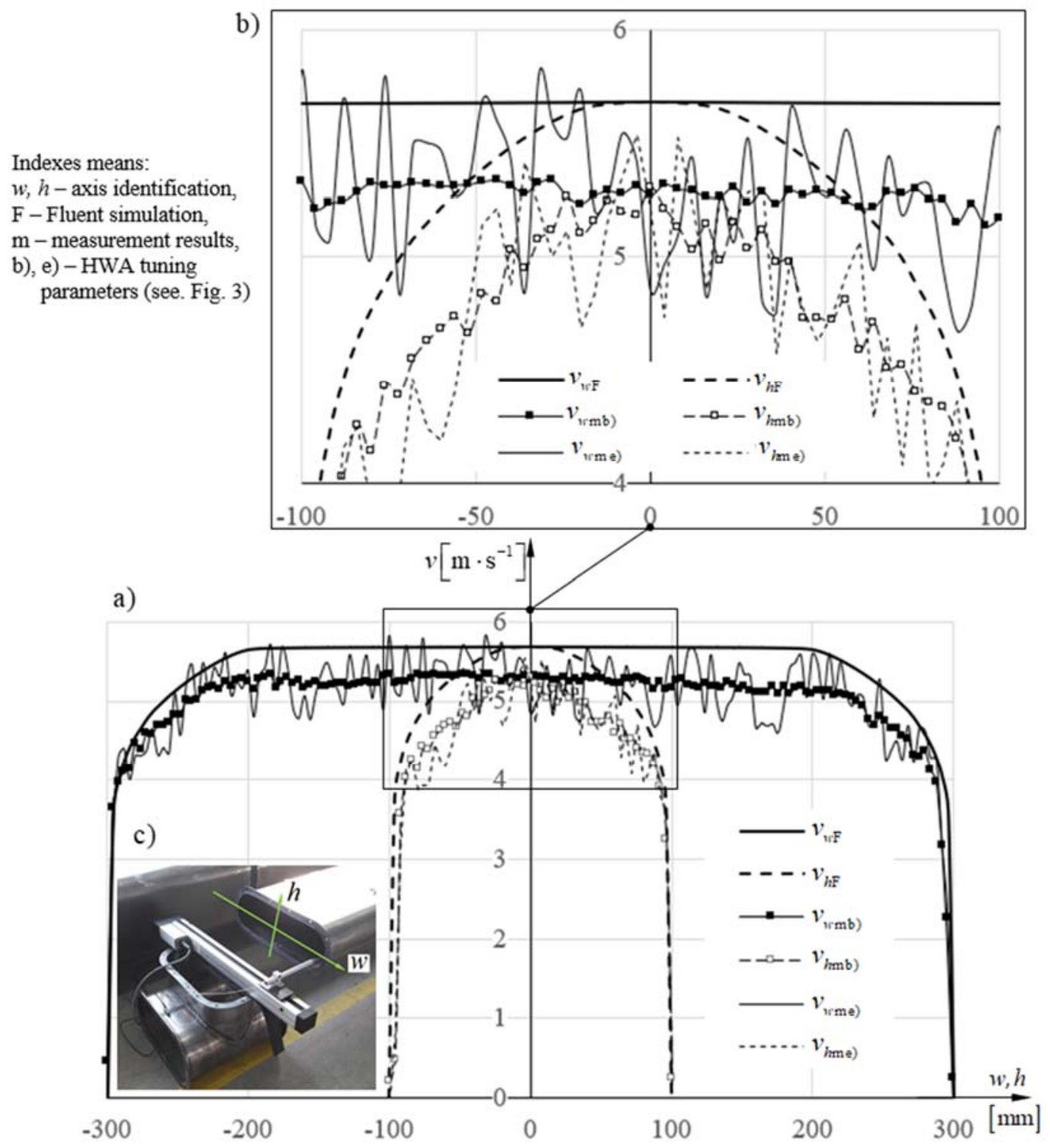

Fig. 4: Comparison of measurement results with calculations in the FLUENT code: a) full range of axes $w$ and $h ; b$ ) velocity detail around duct symmetry point; c) photograph of the HWA test stand.

A hot-wire anemometer (DANTEC, StreamLine System CTA90) was used to measure the velocity distribution. It works in Constant Temperature Anemometry (CTA) mode. Measurement probe was onewire DANTEC, model 55P16. Data acquisition was carried out using the NATIONAL INSTRUMENTS, 
AT-MIO-16E-10 measuring card. The probe shifts were carried out using the Light Weight Traverse (41T85) uniaxial traverser system which cooperates with above anemometer. The range of motion, the distance between measuring points is defined before the start of measurements in the form of a series of numerical values specifying the location of the measuring points. The choice of linear probe motion and the interval between measurements was carried out in the Stream Ware program.

Tab. 1: Average values of velocity for each measurements series carried out.

\begin{tabular}{|c|c|c|c|c|c|c|}
\hline Series & a) & b) & c) & d) & e) & f) \\
\hline Time of measurement [s] & $t_{\text {a) }}=26.21$ & $t_{\mathrm{b})}=4.096$ & $t_{\mathrm{c})}=8.467$ & $t_{\mathrm{d})}=0.127$ & $t_{\mathrm{e})}=0.233$ & $t_{\mathrm{e})}=0.007$ \\
\hline Average velocity $[\mathrm{m} / \mathrm{s}]$ & 5.616 & 5.656 & 5.619 & 5.602 & 5.908 & 5.628 \\
\hline Relative error [\%] & 0.98 & 0.27 & 0.93 & 1.22 & -4.16 & 0.76 \\
\hline
\end{tabular}

Selected results of air velocity measurements realized in the symmetry axis $w$ and $h$ for the assumed values of sampling frequency and number of samples are presented in Fig. 4. There are the results of measurements for the set $f=1 \mathrm{kHz}$ and $n=4096$ samples, next set $f=1 \mathrm{kHz}$ and $n=8$ samples, and the result of the flow simulation implemented in the FLUENT application.

\section{Conclusions}

Based on the results in Tab. 1, the parameters: sampling frequency $f=1 \mathrm{kHz}$ and number of samples $n=4096$ were used during the tests, these parameters provided sufficiently good measurement quality in the acceptable time of one measurement, $t_{\mathrm{b})}=4096 / 1000=4.096 \mathrm{sec}$. The total measurement time after adding the probe travel time and the time to wait for the stream stabilization did not exceed $t_{\mathrm{m}}=5 \mathrm{sec}$. The results presented in Figs. $3 \mathrm{a}$ and $3 \mathrm{~b}$ using a time of $t_{\mathrm{m}}=0.008 \mathrm{sec}$ were characterized by a large dispersion, did not give a sufficiently smooth distribution curve. It should be remembered that the probe was one-wire, so it was impossible to determine in the direction of flow. The number of samples $n=8$ also introduced another negative conclusion - tests carried out at the same point were characterized by a significant dispersion which was not observed for the equal $n=4$ 096. A similar analysis that also gave positive results was done in Smyk et al., 2017.

Conducted measurements were industrial research (Peszyński, 2018). They are characterized by lower accuracy required. Tested ducts also deviated from ideal, were not uniform along the length $L$. They consisted of segments with length $L=1 \mathrm{~m}$ equal (smaller cross-sections) or $L=1.8 \mathrm{~m}$ (larger crosssections). Undoubtedly a significant disruption of flow was caused by seals between segments. This finding was later proved by results in measuring the major (linear) losses in the ducts (Peszyński, 2019).

\section{Acknowledgement}

The authors would like to kindly thank the company Nucair Technologies Sp. z o.o., Solec Kujawski, Poland for the performance of tested ducts and delivery of the air supply system. Authors also received institutional support BS 28/2018 granted by Faculty of Mechanical Engineering of UTP University.

\section{References}

Brunn H. H. (1995) Hot-wire anemometry. Principles and signal analysis" Oxford University Press. Oxford, ISBN 0-19-856342-6.

Dantec Stream Line Documentation (1996) Dantec Measurement Technology A/S.

Peszyński, K. (2018) Building a bridge between industry and theory on the example of a new ventilation system. International Conference Experimental Fluid Mechanics 2018, pp. 9-14.

Peszyński, K. (2019): Linear Pressure Losses Coefficients in a New Ventilation System. Proceedings of $25^{\text {th }}$ International Conference Engineering Mechanics 2019, Svratka, Czech Republic, pp. 279-282.

Peszyński, K., Olszewski, L., Smyk, E., Kasprowicz, T. (2017) Development of New Type Ventilation Ducts System, Proceedings of $23^{\text {rd }}$ International Conference Engineering Mechanics 2017, Svratka, Czech Republic, pp. 50-53.

Smyk, E., Wawrzyniak, S., Perczyński, D., Kolber, P. (2017) Axisymmetric Valve with Synthetic Jet Actuator. Proceedings of $23^{\text {rd }}$ International Conference Engineering Mechanics 2017, Svratka, Czech Republic, pp. 886-889. 